\title{
In vitro Propagation of Holarrhena antidysenterica Wall., Wedelia chinensis (Osb.) Merr. and Woodfordia fruticosa (L.) Kurz.
}

\section{S.A.M. Nurul Islam*, Haradhan Banik ${ }^{1}$, Saiful Alam M. Tarek and Mahbubur Rahman}

Bangladesh Forest Research Institute, Sholashahar, P.O.Box-273, Chittagong, Bangladesh

Key words: Medicinal plant, Holarrhena antidysenterica, Wedelia chinensis, Woodfordia fruticosa, In vitro cloning, Multiple shoot

In vitro multiple and axillary shoots were induced from apical shoot tips and nodal buds of Holarrhena antidysenterica, Wedelia chinensis and Woodfordia fruticosa in MS supplemented with BAP (0.5 - $3.0 \mathrm{mg} / \mathrm{l}$ and $\mathrm{Kn}(0.5-1.0 \mathrm{mg} / \mathrm{l})$. GA3 was suitable for elongation of shoot and production of healthy shoots in Woodfordia fruticosa. Huge multiple shoots with aerial tiny roots were produced in the culture medium containing BAP. Excised shoots of Wedelia chinensis and Woodfordia fruticosa rooted when they were cultured in half strength of MS containing IBA $(1.0 \mathrm{mg} / \mathrm{l})$ but Holarrhena antidysenterica produced roots only when medium was supplemented with NAA $(1.0-3.0 \mathrm{mg} / \mathrm{l})$. The rooted shoots of these three species were successfully acclimatized and established in the soil. They were vigorously growing in nature. Wedelia chinensis and Woodfordia fruticosa produced profuse branching and flowered earlier in nursery within 12 15 weeks.

The present investigation was undertaken to develop techniques for rapid regeneration of these species. Young growing shoots of Kurchii $(H$. antidysenterica), Mohabhingaraj (Wedelia chinensis) and Dhaiphul (W. fruticosa) were collected from adult plants. Apical tips and nodal buds were cut into small pieces (5 - $10 \mathrm{~mm}$ long) and used as explants. They were sterilized with $0.1 \%$ $(\mathrm{w} / \mathrm{v})$ mercuric chloride in water solution for ten $\mathrm{min}$ and then washed with autoclaved distilled water. The explants were inoculated in MS supplemented with BAP or NAA. Then BAP, Kn and GAs were supplemented in MS for multiple shoots induction and elongation.

\footnotetext{
*Author for correspondence. <nislam@ctpath.net ><samnislam@yahoo.com> ${ }^{1}$ Forest Department, Bangladesh. $<$ banikhd@yahoo.com $>$.
} 
All the culture media were gelled with agar $(7 \mathrm{~g} / \mathrm{l})$ and $\mathrm{pH}$ was adjusted at 5.8 before autoclaving. Growth room was maintained with temperature at $27 \pm 2^{\circ} \mathrm{C}$ and 16 hours light and 8 hours dark period. Half strength of MS supplemented with IBA and NAA were used for root induction. Rooted plantlets thoroughly washed under running tap water were kept in culture tube in water for two three days in the growth room. Then the plantlets were transferred in soil (soil filled pots and nursery beds maintaining high humidity) in the nursery.

The explants of $H$. antidysenterica started growing in MS supplemented with BAP and NAA within two weeks. Buds developed on the axils of leaves in MS with BAP. Multiple shoots developed in MS using the combination of BAP and Kn (Fig. 1) but shoots elongated more with GA3.
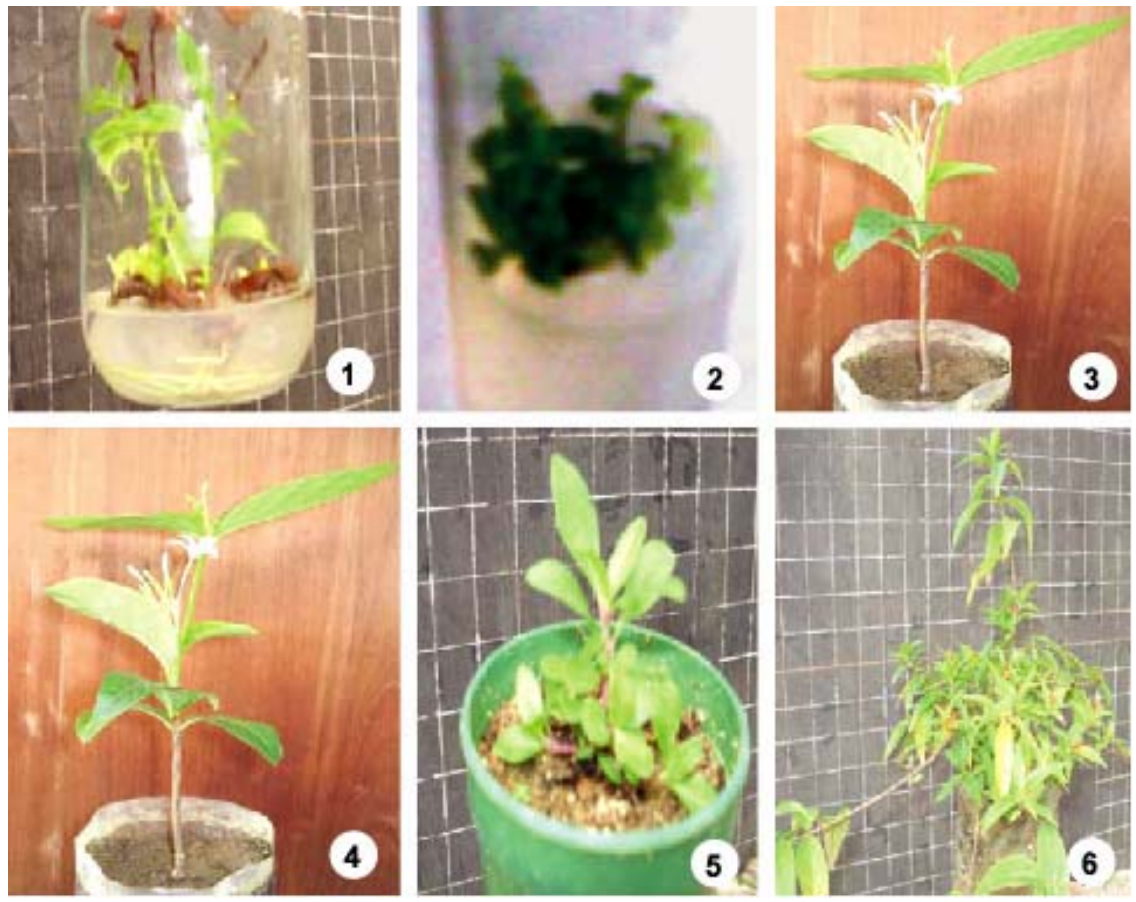

Figs. 1-3: In vitro multiple shoots of Holarhena antidysentirica, Wedelia chinensis and W. fruticosa, respectively. Fig. 4. Plantlet of $H$. antidysentirica in polybag. Fig. 5. Plantlet of Wedelia chinensis in pot. Fig. 6. Plantlet of W. fruticosa in polybag.

MS supplemented with BAP was used to establish the culture of Wedelia chinensis and $W$. fruticosa. Wedelia chinensis produced multiple shoots in MS supplemented with BAP but more multiple or elongated shoots were observed when $\mathrm{Kn}$ and GAз were added in the medium (Fig. 2).

$W$. fruticosa was cultured in MS supplemented with BAP alone and in combination with $\mathrm{Kn}$ or $\mathrm{GA}_{3}$. Shoot proliferation and multiplication were 
observed after inoculation of shoot tips. They grew thicker and elongated with numerous shoots with very small leaves on it. Then the shoots were separated in clusters or individually. It was also observed that 400 - 700 shoots (Fig. 3) grew in $250 \mathrm{ml}$ culture bottles on the eighth week of culture. Some shoots grew singly or with 2 - 5 branches. Thin aerial roots grew on shoots but they did not enter into medium.

Root induction of $H$. antidysenterica was observed in half strength of MS with NAA, maintaining a dark and low light intensity. It was found that in presence of IBA in the medium, callus grew on the cut end of shoot base (Table 1). Both Wedelia chinensis and W. fruticosa rooted and elongated in half strength of MS supplemented with IBA.

Rooted plantlets easily adapted in soil and coconut husk filled polybags/pots maintaining high humidity and partial shade. The potting mixtures that allowed adequate drainage and aeration had been recommended for acclimatization of in vitro regenerated plants (Dustan and Turner 1984 and Kozai et al. 1987) and success has been obtained with soil-free potting mixture like vermiculite, partite, peat plug or small foam blocks (Miller 1983 and McCrown 1986). Plantlet of $H$. antidysenterica grew erect without branchingt in polybags (Fig. 4). Plantlets of Wedelia chinensis and Woodfordia fruticosa produced much branching (Figs. 5, 6) in polybags filled with soil and in the nursery bed. These plantlets flowered on transfer to pots and nursery beds within 12 - 15 weeks. In vitro flowering was not observed but earlier flowering habit expressed in those plantlets of three species after transfer in the soil and similar flowering habit showed in Ipecac (Cephaelis ipecacuantha Rich.) in tissue culture derived plants (Chaudhuri and Jha 2008).

\section{Referencses}

Chaudhuri RK and Jha TB (2008) Conservation and Production of Ipecac (Cephaelis ipecacuanha Rich.) Plants from Long Term Shoot Cultures. Plant Tissue Cult. \& Biotech. 18(2): 156-164.

Dustan DI and Turner KE (1984) The acclimatization of micropropagated plants. In: Cell Culture and Somatic Cell Genetics of Plants, Vol. 1 Laboratory Procedures and Their Applications, Vasil IK (Ed.), Academic Press, Orianddo, pp. 123-129.

Kozai T, Hyashii M, Mirosawa Y, Kodama T and Watanabe I (1987) Environmental control of in vitro cultured plants (1) acclimatization unit for accelerating the plantlet growth and the test tube cultivation. J. Agr. Met. Jpn. pp. 349-358.

Miller D (1983) Watering and growing-on of the micropropagated plants. Comb. Proc. Intl. Plant Prop. Soc. 33: 353-256.

McCrown DD (1986) Plug systems of micropropagules. In: Tissue culture as a Plant Production system for Horticultural Crops. Zimmerman HR, Griesbach RJ, Hammerschlag FA and Lawson RH (Eds.) Martinus Nijhoff Dordrecht, pp. 53-60. 